\title{
Is minimally invasive surgical treatment justified for severe acute necrotizing pancreatitis patients with dysfunction of two or more organ systems?
}

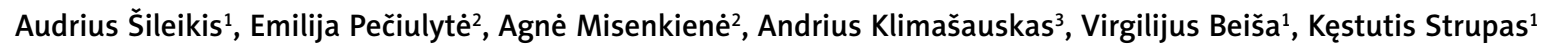 \\ ${ }^{1}$ Clinic of Gastroenterology, Nephrourology and Surgery, Centre of Abdominal Surgery, Vilnius University, Vilnius, Lithuania \\ ${ }^{2}$ Faculty of Medicine, Vilnius University, Vilnius, Lithuania \\ ${ }^{3}$ Clinic of Anaesthesiology and Intensive Care, Vilnius University, Vilnius, Lithuania
}

Videosurgery Miniinv 2017; 12 (3): 225-230

DOI: https://doi.org/10.5114/wiitm.2017.68792

\begin{abstract}
Introduction: When minimally invasive therapy was introduced, it became possible to cure some patients without open surgery, or at least delay the operation for longer than a month.

Aim: To determine the optimal timing to operate on patients with severe acute necrotizing pancreatitis based on the severity of organ insufficiency.

Material and methods: A retrospective analysis was performed in all severe acute necrotizing pancreatitis patients treated in Vilnius University Hospital Santaros Klinikos (VUL SK) from 2007 to 2016. The patients were divided into groups based on the number of dysfunctional organ systems (one or more) and whether the minimally invasive stepup approach to treatment was used.

Results: The patients with one organ dysfunction had a delay of 35 (without the step-up approach) and 36 (with the step-up approach) days before the open surgery, while the patients with two or more organ systems' dysfunction had almost an identical delay of 28 days, using both surgical treatment methods. The mortality of the patients who had one organ dysfunction and in whom the step-up approach was used was $0 \%$, while in patients without the step-up approach it was $41.7 \%$. In the two or more organ systems' dysfunction group, the mortality for those treated with a step-up approach was $64.3 \%$, and without it $70.7 \%$.

Conclusions: The surgical treatment should be initiated with a minimally invasive procedure. Additionally, the surgery on patients with two or more organ systems' dysfunction should not be delayed for more than one month.
\end{abstract}

Key words: severe necrotizing pancreatitis, open necrosectomy, minimally invasive surgery.

\section{Introduction}

A breaking point in the treatment of patients with severe acute necrotizing pancreatitis has been reached, moving from early surgical intervention to maintenance therapy, within the first 2 weeks of the onset of symptoms. It was started after several studies showed high morbidity with early surgical interventions. The authors of one prospective ran- domized study reported that the mortality rate was $58 \%$ for patients who underwent surgery within 42-72 h after the onset of symptoms, and the patients who underwent surgery after more than 12 days from the onset of symptoms had a mortality rate of $27 \%$ [1]. Other studies confirmed these results, but some authors have suggested that surgery should be delayed for at least a month or longer from the onset

\section{Address for correspondence}

Audrius Šileikis, Clinic of Gastroenterology, Nephrourology and Surgery, Center of Abdominal Surgery, Vilnius University, Santariškių 2,

LT-08661 Vilnius, Lithuania, phone: +370 5 2365250, fax: +370 5 2365101, e-mail: audrius.sileikis@santa.It 
of the disease, and it should be performed only if acute necrotizing pancreatitis infection is confirmed and/or the pain continues, and the current patient condition would not allow one to wait for the inflammatory process to subside $[2,3]$.

The improvements of radiology diagnostics and changes of treatment methods of the disease, such as minimally invasive radiologic, endoscopic and laparoscopic procedures, allowed for some patients to completely avoid the surgery and open necrosectomy [4, 5], and for some to delay the onset of sepsis and undergo open necrosectomy even in the $6^{\text {th }}$ or $8^{\text {th }}$ week, which decreases the mortality rate. However, the majority of international treatment guidelines recommend performing open surgical necrosectomy in the $4^{\text {th }}$ week [6-8].

It has also been claimed that acute necrotizing pancreatitis surgical treatment will become obsolete. Despite the new critical care technologies, such as extracorporeal cytokine filtering and extracorporeal membrane oxygenation, and deeper knowledge of pancreatitis, such as the progress of the disease and progress of the minimally invasive approach, the need for open surgery still exists. Now, a lot of centres are using the step-up approach based on the PANTER study, published in 2010, which resulted in other minimally invasive technique studies, like TENSION, PUINGUIN and POINTER. Vilnius University Hospital Santaros Klinikos also uses the step-up approach [9]. However, it is not always technically possible to implement it in daily practice, and there is a high risk of uncontrollable septic status.

Due to continuous discussion on when it is best to operate on patients with acute necrotizing pancreatitis, Vilnius University Hospital Santaros Klinikos conducted a retrospective study of the patients treated in the clinic, by comparing the treatment results with the timing of the surgical intervention, hoping to find out the optimal time for surgical treatment in acute necrotizing pancreatitis.

\section{Material and methods}

A retrospective cohort analysis was performed, in which all patients treated in VUL SK from 2007 to 2016 for severe acute pancreatitis were selected. Patients were evaluated based on the updated Atlanta classification [10], and the ones who underwent surgical treatment were singled out. Only those patients who were treated from 2007, developed one or several organ systems' dysfunction within the first 3 days, and underwent open surgery were analysed. These patients were divided into groups based on whether the step-up approach was used or not. The purpose of dividing patients into the groups was to determine which group of patients benefits from the step-up approach. Patients' demographic data, time until the open surgery, duration of hospitalization, pancreatic and surrounding tissue changes according to computed tomography severity index (CTSI) [11], postoperative complications, and mortality were evaluated. Also, the results of microbiological culture, obtained during the first surgery, were analysed.

Patients were also divided based on the indications for surgical interventions: 1) had surgery within 2 weeks after the onset of the disease due to systemic inflammatory response complications (mesenteric artery thrombosis, hollow organ perforation, uncontrolled intra-abdominal hypertension, bleeding), emphysematous pancreatitis, iatrogenic pancreatitis (ERCP, post-surgical), 2) when the minimally invasive surgery or open surgery was performed at least 15 days from the onset of the disease due to infected necrosis, proved by fine needle aspiration biopsy (FNA), or radiologically and clinically worsening patient's condition.

Data were processed with SPSS 23 and MS Excel 2013 programs. To conduct the research, permit No. EK-13 (2016.03.03) was obtained from Vilnius University Hospital Santaros Klinikos Clinics' Ethics Committee.

\section{Results}

There were a total of 325 patients treated in Vilnius University Hospital Santaros Klinikos (VUL SK) for severe acute necrotizing pancreatitis from 2007 to 2016 (within 10 years).

Metabolic pancreatitis was diagnosed in 210 (64.6\%) patients, biliary pancreatitis in 104 (32\%) patients, and other origin in 11 (3.4\%) patients. There were 198 (60.9\%) men and 117 (39.1\%) women. The average age of men was $51.1 \pm 17.6$ and of women $60.0 \pm 16.7$.

Out of 325 patients who had severe acute pancreatitis, local complications without organ dysfunction were observed in only 54 (16.6\%) patients.

There were 271 (83.4\%) patients with organ system dysfunction: 101 (31.1\%) patients had one organ dysfunction with local complications, and 170 
Table I. Patients' mortality depending on organ systems' dysfunction

\begin{tabular}{|c|c|c|c|c|c|c|c|c|}
\hline \multirow[t]{2}{*}{ Variable } & \multicolumn{4}{|c|}{ One organ system dysfunction } & \multicolumn{4}{|c|}{ Two or more organ systems' dysfunction } \\
\hline & $\begin{array}{c}\text { Treated } \\
\text { conserva- } \\
\text { tively }\end{array}$ & $\begin{array}{c}\text { Op. } \\
<2 \text { weeks }\end{array}$ & $\begin{array}{c}\text { Op. } \\
>2 \text { weeks }\end{array}$ & Total & $\begin{array}{c}\text { Treated } \\
\text { conserva- } \\
\text { tively }\end{array}$ & $\begin{array}{c}\text { Op. } \\
<2 \text { weeks }\end{array}$ & $\begin{array}{c}\text { Op. } \\
>2 \text { weeks }\end{array}$ & Total \\
\hline Patients & 48 & 27 & 26 & 101 & 57 & 44 & 69 & 170 \\
\hline Deaths & 0 & $7(6.9 \%)$ & $5(4.9 \%)$ & 12 (11.8\%) & 15 (8.8\%) & $24(14.1 \%)$ & 47 (27.6\%) & $86(50.6 \%)$ \\
\hline
\end{tabular}

(52.3\%) patients had two or more organ systems' dysfunction with local complications (Table I).

In patients with one organ system dysfunction the overall mortality rate was $11.8 \%$, and in those with two or more organ systems' dysfunction it was $50.6 \%$.

Upon analysing the mortality of patients having one organ system dysfunction, it was found that the mortality rate was similar: $25.9 \%$ of those operated on within the first 2 weeks due to iatrogenic complications or complications caused by systemic inflammatory response; and $19.2 \%$ when the surgery was performed later because of the patient's septic status.

Comparing the mortality of patients with two or more organ systems' dysfunction, higher mortality rates were observed in those who were operated on later due to septic complications (68.1\%) vs. those operated on within 2 (54.4\%) weeks.
Out of 95 patients a step-up approach to treatment was used on 42 (44.2\%) patients. Open necrosectomy was performed on 53 (55.8\%) patients. In the step-up group, the sonoscopic drainage was performed on 28 (66.7\%) patients, retroperitoneal necrosectomy on 14 (33.3\%), and both sonoscopic drainage and retroperitoneal necrosectomy on 5 (11.9\%) patients.

By comparing these groups, it was concluded that male to female ratio, computed tomography severity index (CTSI), the number of reoperations and complications, and overall hospitalization length of survived patients were not different. The rate of microbiologically proven infected pancreatic necrosis was not significantly different: in the step-up group $85.7 \%$, and in the operated patients' (no step-up) group $79.2 \%$ (Table II).

Table II. Patients treated with the step-up approach, and patients who had necrosectomy without a step-up

\begin{tabular}{|c|c|c|c|c|c|}
\hline \multirow{2}{*}{$\begin{array}{l}\text { Parameter } \\
\text { Number of patients }\end{array}$} & \multicolumn{2}{|c|}{$\begin{array}{c}\text { Treated by step-up approach } \\
\text { technique }\end{array}$} & \multicolumn{2}{|c|}{$\begin{array}{c}\text { Treated without step-up approach } \\
\text { technique }\end{array}$} & \multirow[t]{2}{*}{$P$-value } \\
\hline & 42 & $45.7 \%$ & 53 & $54.4 \%$ & \\
\hline \multicolumn{6}{|l|}{ Gender: } \\
\hline Women & 15 & $35.7 \%$ & 19 & $35.9 \%$ & \\
\hline Men & 27 & $64.3 \%$ & 34 & $64.2 \%$ & \\
\hline Average age [years] & $47.5 \pm 15.4$ & & $56.5 \pm 16.1$ & & 0.050 \\
\hline $\begin{array}{l}2 \text { or more organs' } \\
\text { dysfunction }\end{array}$ & 28 & $66.7 \%$ & 41 & $77.4 \%$ & \\
\hline CTSI & $7.9 \pm 1.7$ & & $7.6 \pm 1.9$ & & 0.597 \\
\hline 2 or more operations & $2.6 \pm 1.9$ & & $2.7 \pm 2.2$ & & 0.850 \\
\hline $\begin{array}{l}\text { Hospital stay of dis- } \\
\text { charged patients [days] }\end{array}$ & $91.3 \pm 39.1$ & & $97.2 \pm 33.2$ & & 0.599 \\
\hline Preoperative time [days] & $32.5 \pm 19.2$ & & $28.8 \pm 14.0$ & & 0.626 \\
\hline $\begin{array}{l}\text { Complications (fistulas, } \\
\text { bleeding, or both) }\end{array}$ & 19 & $45.2 \%$ & 38 & $71.7 \%$ & 0.150 \\
\hline $\begin{array}{l}\text { Infection of pancreatic } \\
\text { necrosis }\end{array}$ & $85.7 \%$ & & $79.3 \%$ & & 0.311 \\
\hline Mortality & 18 & $42.9 \%$ & 34 & $64.2 \%$ & 0.0116 \\
\hline
\end{tabular}




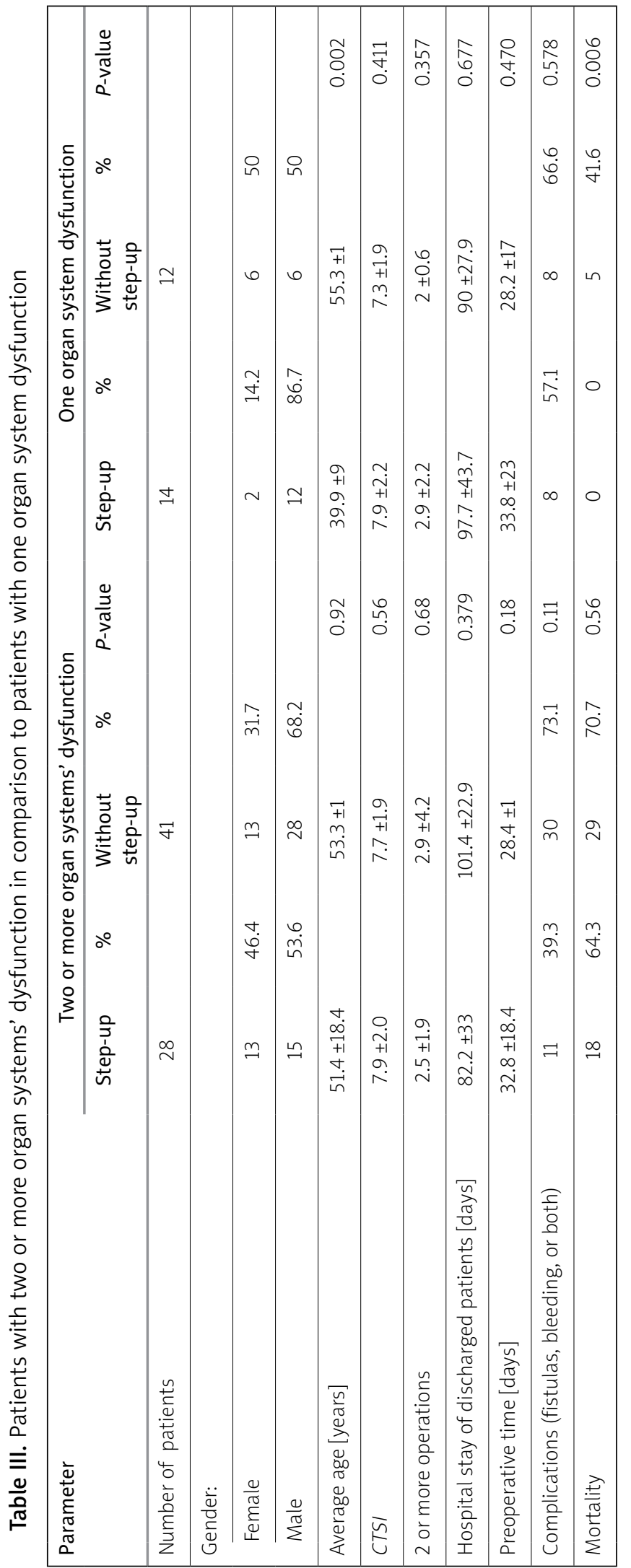

The average age of patients with the step-up approach was 47.5 years, without the step-up approach 56.5 years. With the step-up approach 18 out of $42(42.9 \%)$ patients died, and without the step-up approach 34 out of 53 (64.2\%) died.

By comparing the patients with one organ system dysfunction vs. two or more organ systems' dysfunction, we could conclude that patients with one organ dysfunction had a delay of 35 (without the step-up approach) and 36 (with the step-up approach) days before the open surgery, while the patients with two or more organ systems' dysfunction had an almost identical delay of 28 days, using both surgical treatment methods (Table III).

Out of 26 patients with one organ system dysfunction, when a step-up approach was used, 5 (11.9\%) did not need open surgery and no one from that group died, while $5(41.7 \%)$ out of 12 without the step-up approach died. We never performed open surgery after successful step-up approach treatment. The overall mortality rate of patients with one organ system dysfunction and a step-up approach to treatment was $19.2 \%$.

In the two or more organ systems' dysfunction group (69 patients) 47 (68.1\%) patients died. Out of those, the mortality in the step-up group was 18 out of 28 (64.3\%), and in no step-up group 29 out of 41 (70.7\%). The number of complications was not significantly different.

\section{Discussion}

Severe acute necrotizing pancreatitis, with mortality risk from 8 to $39 \%$, develops in $20 \%$ of patients with severe acute pancreatitis [12]. The most common cause of death is early organ dysfunction, infection of peripancreatic tissue or pancreatic necrosis, predisposing sepsis and multiple organ dysfunction syndrome (MODS) [13].

It was thought previously that half of the patients die due to systemic inflammatory response syndrome (SIRS) and induced acute intra-abdominal complications in the first 2 weeks, and the other half due to septic complications, caused by the infection of pancreatic necrosis [14].

Despite early and conservative treatment with immunomodulators, antibiotics [15], haemofiltration, cytokine filters and enteral nutrition [16] within the first days of the disease, the mortality rate within the first 2 weeks of the disease onset starts at $50 \%$. Our data showed $46.9 \%$ (46 out of 98 ) [17]. 
So, the new challenge is to change the tactics of the surgical intervention, hoping to decrease the mortality from septic complications: start using the step-up approach widely and delay the surgery for as long as possible.

In 2010 New England Journal of Medicine published the PANTER study - the minimally invasive step-up approach compared with open necrosectomy in patients with severe necrotizing pancreatitis. The benefits of this multicenter study are: using minimally invasive methods in comparison with open necrosectomy, and decreasing the number of major complications in patients who had severe acute necrotizing pancreatitis and infected necrosis [18].

The PANTER study showed that the mortality in the groups did not differ significantly $(19 \%$ of patients with open necrosectomy, and $16 \%$ with the step-up approach). But MODS develops more rarely in the step-up approach, $12 \%$ vs. $40 \%$ [18].

The PINGUIN study showed that when applying TENSION (transluminal endoscopic necrosectomy), the SIRS decreases: IL6 concentration in the blood decreases in comparison to minimally invasive surgery. Development of MODS - 0\% vs. $50 \%$, and less pancreatic fistulas, $10 \%$ vs. $70 \%$ [8].

However, our analysis of the results showed that the step-up approach is only effective for the severe acute necrotizing pancreatitis patients with one organ dysfunction. There was a statistically significant decrease of mortality. In patients with two or more organ systems' dysfunction, we did not find any statistically significant decrease in mortality, but there is a probability of $50 \%$.

Another possibility to increase the survival rate is to delay the surgery as much as possible. International guidelines recommend delaying catheter drainage up to 4 weeks from the onset of symptoms until the necrotic masses separate. However, we had to perform the minimally invasive interventions in patients with proven pancreatic necrosis infection earlier. The indications for intervention in a sterile necrotizing pancreatitis (4-8 weeks from the onset of symptoms) are: persistent gastrostasis, caused by pancreatic and/or peripancreatic tissue oedema due to acute pancreatitis, intestinal or biliary obstruction, other persisting symptoms such as pain and shutting pancreatic syndrome [19].

What is the optimal time for intervention? It is stated that the interventions should be avoided within 2 weeks of the onset of severe acute necro- tizing pancreatitis. During this period, a lot of patients may require intensive treatment in the intensive care unit due to progressive organ dysfunction, which is associated with high mortality [20]. Early intervention in the pancreatic or peripancreatic inflamed tissues does not increase the survival rate. There are rare exceptions, when surgical treatment is needed: intra-abdominal bleeding, intestinal necrosis. In any case, if it is at all possible, it is best not to touch the inflamed pancreas in the first 2 weeks [21]. Pancreatic necrosis usually separates within 3-5 weeks from the onset of symptoms. Several observational studies have indicated that a better solution would be to perform the surgery more than 28 days after the onset of the disease [21, 22]. Some authors state that delaying the surgery for more than 28 days worsens the overall condition of the body due to nutritional and immune deficiency.

Antibiotics can delay the onset of infected necrosis intervention by up to 4 weeks [23]. Indications for the intervention are: suspected or confirmed necrotic infection, persisting organ dysfunction for several weeks without signs of infection, demarcated infected necrosis, pain or ileus [24]. It was discussed whether by applying the step-up approach it is possible to delay the necrosectomy time by $6-8$ weeks. However, data from some studies show that after 6-8 weeks festering occurs, and it can be difficult to open the abscess [25].

All our data showed that delaying surgery is only possible in the patients with one organ system dysfunction, whether the step-up approach was used or not. Patients with the step-up approach survived.

In patients with two or more organ systems' dysfunction, whether the step-up approach was successful or not, our surgery was performed on the $28^{\text {th }}$ day and the mortality was almost the same in both groups $-70 \%$. Also, infected pancreatic necrosis was confirmed in $85.7 \%$ of all step-up approach patients. The minimally invasive surgical treatment was not sufficient for any patients. All of them had to undergo open surgery.

\section{Conclusions}

After analysis of our findings, we concluded that the main factor determining mortality is the severity of organ dysfunction, and all efforts need to be directed toward its prevention and appropriate treatment. The step-up approach improves surviv- 
al in patients with one organ system dysfunction. The step-up approach is not as effective in patients with two or more organ systems' dysfunction, and it is only technically possible in $50 \%$ of Lithuanian patients. Despite this, the surgical treatment should be initiated with a minimally invasive procedure if possible. In patients with two or more organs' dysfunction, the surgery should not be delayed for more than one month.

\section{Conflict of interest}

The authors declare no conflict of interset.

\section{References}

1. Mier J, Leon E, Castillo A, et al. Early versus late necrosectomy in severe necrotzing pancreatitis. Am J Surg 1997; 173: 71-5.

2. Uhl W, Warshaw A, Imrie C, et al. IAP Guidelines for the surgical management of acute pancreatitis. Pancreatology 2002; 2: 565-73.

3. United Kingdom guidelines for the management of acute pancreatitis. Gut 1998; 42 Suppl 2: S1-13.

4. Jagielski M, Smoczynski M, Adrych K. Transpapillary drainage of pancreatic parenchymal necrosis. Videosurgery Miniinv 2015; 10: 491-4.

5. Smoczynski M, Jagielski M, Jabłonska A, Adrych K. Endoscopic necrosectomy under fluoroscopic guidance - a single center experience. Videosurgery Miniinv 2015; 10: 237-43.

6. Working Group IAP/APA Acute Pancreatitis Guidelines. IAP/APA evidence-based guidelines for the management of acute pancreatitis. Pancreatology 2013; 13 (4 Suppl. 2): e1-15.

7. Tenner S, Baillie J, DeWitt J, Vege SS. American College of Gastroenterology guideline: management of acute pancreatitis. Am J Gastroenterol 2013; 108: 1400-15.

8. The Italian Association for the Study of the Pancreas (AISP). Consensus guidelines on severe acute pancreatitis. Dig Liver Dis 2015; 47: 532-43.

9. Šileikis A, Beiša V, Simutis G, et al. Three-port retroperitoneoscopic necrosectomy in management of acute necrotic pancreatitis. Medicina (Kaunas) 2010; 46: 176-9.

10. Banks PA, Bollen TL, Dervenis C, et al. Classification of acute pancreatitis-2012: revision of the Atlanta classification and definitions by international consensus. Gut 2013; 62: 102-11.

11. Karpavičius A, Dambrauskas Ž, Samuilis A, et al. [The value of clinical and radiological scores for acute pancreatitis severity and complications assessment. The results of the multicenter prospective study]. Perspektyvinio daugiacentrio kohortinio tyrimo rezultatai. Medicinos teorija ir praktika [Theory and Practice in Medicine] 2015; 21: 814-21.

12. Banks PA, Freeman ML. Practice guidelines in acute pancreatitis. Am J Gastroenterol 2006; 101: 2379-400.

13. Whitcomb DC. Acute pancreatitis. N Engl J Med 2006; 354: 2142-50.

14. Mofidi R, Duff MD, Wigmore SJ, et al. Association between early systemic inflammatory response, severity of multiorgan dys- function and death in acute pancreatitis. Br J Surg 2006; 93: 738-44.

15. Dugernier T, Reynaert M, Laterre PF. Early multi-system organ failure associated with acute pancreatitis: a plea for a conservative therapeutic strategy. Acta Gastroenterol Belg 2003; 66: 177-83.

16. Windsor A, Kanwar S, Li A, et al. Compared with parenteral nutrition, enteral feeding attenuates the acute phase response and improves disease severity in acute pancreatitis. Gut 1998; 42: 431-5.

17. De Campos T, Assef JC, Rasslan S. Questions about the use of antibiotics in acute pancreatitis. World J Emerg Surg. 2006; 1: 20.

18. van Santvoort HC, Besselink MG, Bakker OJ. A step-up approach or open necrosectomy for necrotizing pancreatitis. N Engl J Med 2010; 362: 1491-502.

19. Besselink M, van Santvoort H, Freeman M, et al. IAP/APA Acute Pancreatitis Guidelines. IAP/APA evidence-based guidelines for the management of acute pancreatitis. Pancreatology 2013; 13 (4 Suppl. 2): e1-15.

20. Buter A, Imrie CW, Carter CR, et al. Dynamic nature of early organ dysfunction determines outcome in acute pancreatitis. Br J Surg 2002; 89: 298-302.

21. Besselink MGH, Verwer TJ, Schoenmaeckers EJP. Timing of surgical intervention in necrotizing pancreatitis. Archi Surg 2007; 142: 1194-201.

22. Smoczynski M, Jagielski M, Jabłonska A, Adrych K. Transpapillary drainage of walled-off pancreatic necrosis - a single center experience. Videosurgery Miniinv 2015; 10: 527-33.

23. Rau B, Pralle U, Mayer JM, Beger HG. Role of ultrasonographically guided fine-needle aspiration cytology in the diagnosis of infected pancreatic necrosis. Br J Surg 1998; 85: 179-84.

24. Logue JA, Carter CR. Minimally invasive necrosectomy techniques in severe acute pancreatitis: role of percutaneous necrosectomy and video-assisted retroperitoneal debridement. Gastroenterol Res Pract 2015; 2015: 693040.

25. Abraham M. Pancreatic necrosis and pancreatic abscess. Available at: http://emedicine.medscape.com/article/181264-overview.

Received: 19.04.2017, accepted: 31.05.2017. 